\title{
CAPACITAÇÃO EM BOAS PRÁTICAS DE FABRICAÇÃO E APROVEITAMENTO INTEGRAL DE ALIMENTOS PARA OS MEMBROS DA ASSOCIAÇÃO DE MULHERES DE SALGUEIRO - AMUSA
}

\author{
Autores: Ana Cláudia Siqueira Silva ${ }^{1}$; Vanúsia Medeiros Silva ${ }^{1}$; Liliane Dária Félix ${ }^{1}$; \\ Paulo Garcez Leães ${ }^{2}$; Cristiane Ayala de Oliveira ${ }^{3}$ \\ 1- Graduanda do Curso de Tecnologia em Alimentos, IF Sertão- PE - Campus Salgueiro. \\ 2- Pedagogo, IF Sertão- PE - Campus Salgueiro. \\ 3- Docente do Curso Superior de Tecnologia em Alimentos- Orientadora do Trabalho. cristiane.ayala@ifsertao-pe.edu.br
}

\section{Introdução}

Frutas, hortaliças e seus derivados, bem como carne, leite e seus derivados, têm grande importância no fornecimento de nutrientes essenciais para a nutrição humana. Mas eles apresentam alta perecibilidade, devendo receber atenção muito especial na sua manipulação e nos seus processos de transformação para não virem a configurar problemas de segurança alimentar.

Ao setor alimentício cabe a competência de oferecer ao mercado consumidor, produtos que atendam a todas as exigências deste segmento, ofertando qualidade, inovação e preço acessível. O sucesso deste setor depende, sobremaneira, da geração de produtos de qualidade. A qualidade envolve diferentes aspectos que podem assumir distintos níveis de importância entre o mercado produtor e consumidor e dentro de diferentes segmentos de cada mercado. Normalmente, a qualidade é vislumbrada a partir de aspectos sensoriais, como a aparência, o flavor, e a textura, aspectos de segurança, aspectos nutricionais, conivência e preço. Contudo, durante o processamento e manipulação de alimentos, são gerados "resíduos" que ainda apresentam utilidade e potencial nutricional, gerando perdas e impactos ambientais. Este trabalho teve por objetivo apresentar técnicas adequadas de manipulação e aproveitamento integral de alimentos mostrando como produzir artesanalmente de maneira adequada, com $o$ intuito de obter um produto que atenda aos critérios de qualidade e ofereça segurança ao consumidor.

\section{Relato de Experiência}

Tratou-se um estudo descritivo, de natureza qualitativa, realizado em campo, a definição do modelo do curso considerou o desenvolvimento de um trabalho integrado e interinstitucional, já estabelecido no projeto, que envolveu a Associação das Mulheres de Salgueiro (AMUSA) localizada no bairro COHAB no município de Salgueiro - PE e Instituto Federal de Educação, Ciência e Tecnologia do Sertão Pernambucano - IF Sertão - PE/ Campus Salgueiro. Sendo assim, teve-se como prioridade uma construção coletiva, através de reuniões de consenso para elaboração da proposta do curso. Nosso público foram as mulheres que se encontram em famílias socialmente excluídas do município de Salgueiro, produtoras rurais, donas de casa que ao beneficiarem seus produtos (com higiene, qualidade, tecnologia de produção e comercialização), poderão agregar valor aos mesmos, seja para o consumo familiar ou para comercialização, melhorando assim sua renda. 
Figura

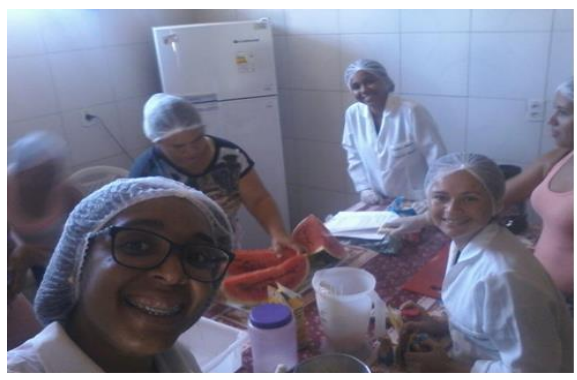

1:
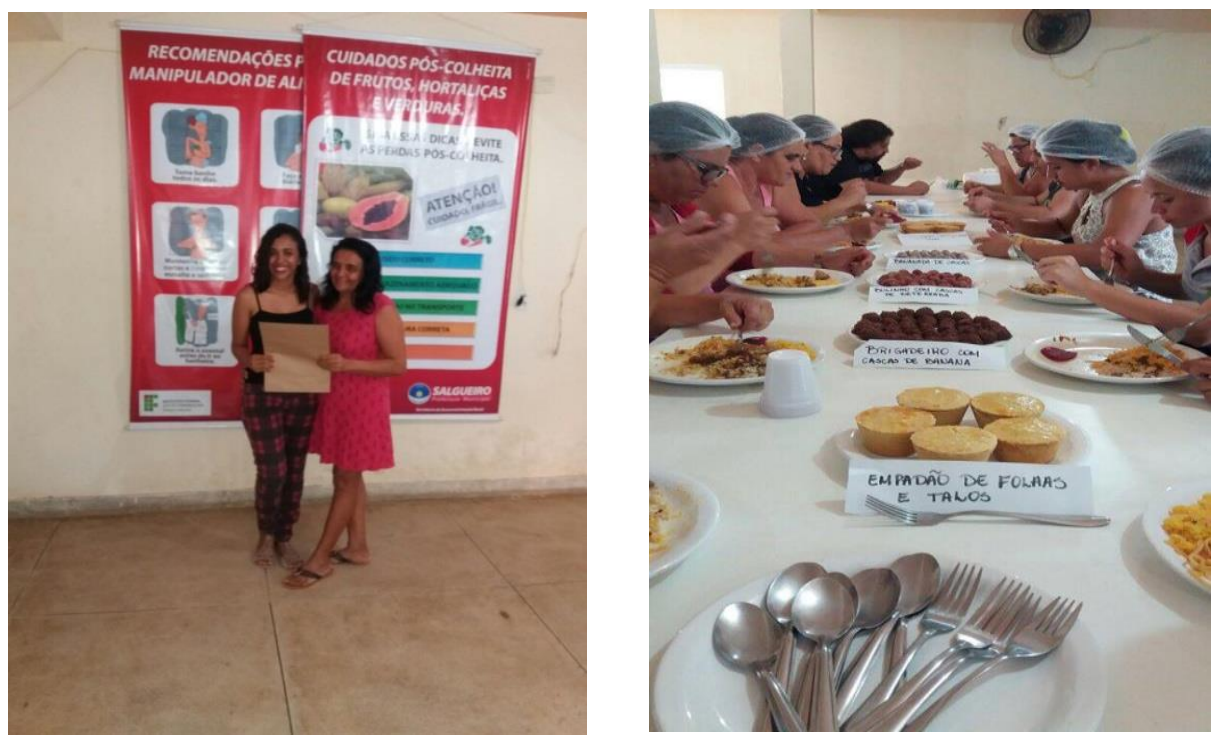

Capacitação das mulheres

Diante disso foram considerados três momentos: sondagem de conteúdos e metodologias junto às merendeiras; desenvolvimento, incluindo o planejamento do curso, sua organização e realização; e avaliação final do curso pelas manipuladoras. Com o curso foi possível reforçar as relações com a higiene do alimento, pessoal e ambiental na manipulação de alimentos, incentivando as mulheres ao aproveitamento integral dos alimentos de forma saudável e atrativa seja visando a comercialização como o consumo familiar. Além de dar noções de controle de qualidade, recebimento e armazenamento correto dos alimentos, orientando sob a correta limpeza dos freezers, fogões, panelas e demais equipamentos e utensílios e capacitando quanto a tecnologia adequada para a produção de derivados do leite e aproveitamento de alimentos (teoria e prática).

\section{Considerações}

A participação no curso contribuiu para com a formação e o desenvolvimento de saberes e competências na área de segurança e aproveitamento dos alimentos, assim, espera-se que com este trabalho tenha-se a possibilidade de gerar um incremento de renda na vida dessas mulheres. Atualmente, as mulheres reúnem-se toda a quarta-feira no prédio da associação para produzir queijos para venda.

\section{Referências Bibliográficas}


BRASIL. Ministério da Saúde. Agência Nacional de Vigilância Sanitária. Legislação. Resoluções. Resolução no 216, de 15 de setembro de 2004: dispõe sobre o Regulamento Técnico de Boas Práticas para Serviços de Alimentação.Brasília: Diário Oficial da União; 16 setembro 2004. Seção I, p. 24-27. 